\title{
A Multivariate Analysis of Correlation between Severity and Duration of Symptoms, Patient Profile and Stage of Endometriosis
}

\author{
Ayalur Gopalakrishnan Radhika*, Sonia Chawla, Priyadrshini Nanda, Garima Yadav, \\ Gita Radhakrishnan \\ Department of Obstetrics \& Gynecology, University College of Medical Sciences and Guru Teg Bahadur Hospital, Delhi, India \\ Email: ${ }^{\star}$ aradhikaag@gmail.com
}

How to cite this paper: Radhika, A.G., Chawla, S., Nanda, P., Yadav, G. and Radhakrishnan, G. (2016) A Multivariate Analysis of Correlation between Severity and Duration of Symptoms, Patient Profile and Stage of Endometriosis. Open Journal or Obstetrics and Gynecology, 6, 615-622. http://dx.doi.org/10.4236/ojog.2016.610077

Received: August 12, 2016

Accepted: September 16, 2016

Published: September 19, 2016

Copyright $\odot 2016$ by authors and Scientific Research Publishing Inc. This work is licensed under the Creative Commons Attribution International License (CC BY 4.0).

http://creativecommons.org/licenses/by/4.0/

\begin{abstract}
Background: Endometriosis is an important cause of infertility and chronic pelvic pain. Our study aims to understand the cause and effect relationship of endometriosis with these two clinical presentations. Objectives: 1) To study the correlation between stage of endometriosis with pain and infertility; 2) To evaluate role of transvaginal ultrasound for diagnosis of endometriosis using laparoscopic diagnosis as gold standard. Methodology: Total of 89 women presenting with infertility and or pain and with laparoscopic findings of endometriosis were included in the study. The results were analysed by logistic regression. Results: The mean age of women was 29.67 years. Seventy three percent of patients had moderate to severe disease while $31.46 \%$ of patients with endometriosis were infertile. Symptom of pain could be categorised as dysmenorrhea (71.47\%), dyspareunia (41.5\%) and dyschezia (15.7\%). There was no association of endometriosis stage with the pain type, duration of symptoms. Transvaginal ultrasound seems a reliable test for diagnosis of ovarian endometriosis and advanced stage disease. $87.5 \%$ of patients with ovarian endometrioma had advanced disease (higher than Stage II rAFS). Conclusion: No correlation was found between the stage of endometriosis and severity of symptoms. Presence of endometrioma on USG was associated with advanced stage of endometriosis.
\end{abstract}

\section{Keywords}

Endometriosis, Infertility, Dysmenorrhoea, Endometrioma

\section{Introduction}

Endometriosis is a distressing chronic disease typically affecting women of reproductive 
age group. Affected women may be totally asymptomatic, or could present with chronic pelvic pain, infertility, dysmenorrhoea, and cyclic urinary or bowel complaints. $\mathrm{Nu}$ merous studies have been conducted enquiring into the association between pain, infertility and stage of disease but existence of casual relationship is still a matter of debate. While some studies Fedele et al. (1990) [1], Mahmood et al. (1991) [2] and Ripps \& Martin (1991) [3] reported no association between stage of disease and severity and frequency of pain symptoms, a positive association between advanced stage disease and dysmenorrhoea was observed by Fedele et al. (1992) [4] and Stovall et al. (1997) [5]. Milingos et al. (2006) [6] and Muzii et al. (1997) [7] reported an association between AFS scoring and severity of dysmenorrhoea. It is documented that endometriosis was present in only $50 \%$ of patients with chronic pelvic pain and $30 \%$ to $80 \%$ of patients with infertility [8]. Gold standard for diagnosis of endometriosis is laparoscopy. Being an expensive and invasive surgical procedure it may cause delays in the diagnosis especially in low resource countries. Diagnostic delay for up to 7 to 12 years is known [9]. Finding a simple, reliable, cheap and non-invasive method could reduce the years of suffering for these women. The present study was conducted with the aim:

1) To study the correlation between stage of endometriosis with pain and infertility.

2) To evaluate the role of abdominal and or transvaginal USG for diagnosis of endometriosis.

\section{Material and Methods}

This prospective cross sectional study was conducted in the department of Obstetrics and Gynecology from years Jan 2013 to December 2013 at Guru Teg Bahadur hospital, DelhiIndia. Consecutive patients presenting during the study period were recruited. Total of 89 women were studied. Inclusion criteria were women presenting with either infertility and/or pain and having laparoscopic findings of endometriosis. Diagnosis of endometriosis was established by visual inspection and grading done according to revised AFS classification at laparoscopy. Morphological type and anatomical location of the implants were also recorded. The exclusion criteria were established diagnosis or laparoscopic findings of other chronic diseases like pelvic inflammatory disease, inflammatory bowel disease, and dense adhesions following past abdominal or pelvic surgery that can cause pelvic pain.

Details of participants including age, parity, chief complaints and their duration, type of pain and infertility were collected. Pain was further categorized into dysmenorrhoea, dyspareunia and dyschezia and recorded as present or absent. Infertility was defined as inability to conceive despite of one year of regular unprotected intercourse. All patients were subjected to trans-abdominal and trans-vaginal sonography. Evidence of endometrioma or other findings including simple ovarian cyst, adnexal mass or adenomyosis were also noted.

Data was analysed using computer software programme SPSS Version 20. Statistical association using odd ratio were determined between stage of disease and clinical variable selected. $\mathrm{P}$ value of $<0.05$ was considered significant. Study was approved by ethics committee of institution. 


\section{Results}

A total of 89 patients participated in the present study. Clinical characteristics of patients are listed in Table 1. Average age of presentation was 29.6 years. Minimal and mild disease (AFS stages $1 \& 2$ ) was present in 10 and 14 patients while moderate and severe disease (AFS stages $3 \& 4$ ) was present in 32 and 33 patients respectively i.e. $73 \%$ of patients had advanced stage disease. Pain was more frequent in women with advanced stage disease (Figure 1). For further analysis of data, women in Stages $1 \& 2$ were grouped as Stage A $(n=24)$ while those with stages $3 \& 4$ were grouped as Stage B $(n=65)$. Dysmenorrhoea was the commonest type for pain experienced $(71.1 \%)$ followed by dyspareunia and dyschezia respectively (Figure 2). Despite the presence of bilateral endometriomas and obliteration of POD, 20 patients with stages 3 or 4 endometriosis did

Table 1. Details of Age, Parity, and stage of endometriosis in patients under study.

\begin{tabular}{ccc}
\hline Age & Number & $\%$ \\
\hline 20 years & 4 & $4.49 \%$ \\
$21-30$ years & 55 & $61.79 \%$ \\
$>30$ years & 30 & $33.70 \%$ \\
Parity & & \\
0 & 48 & $60.75 \%$ \\
1 & 15 & $16.85 \%$ \\
$\geq 2$ & 26 & $29.21 \%$ \\
AFS Stage & & \\
I & 10 & $11.23 \%$ \\
II & 14 & $15.73 \%$ \\
III & 32 & $35.95 \%$ \\
IV & 33 & $37.07 \%$ \\
\hline
\end{tabular}

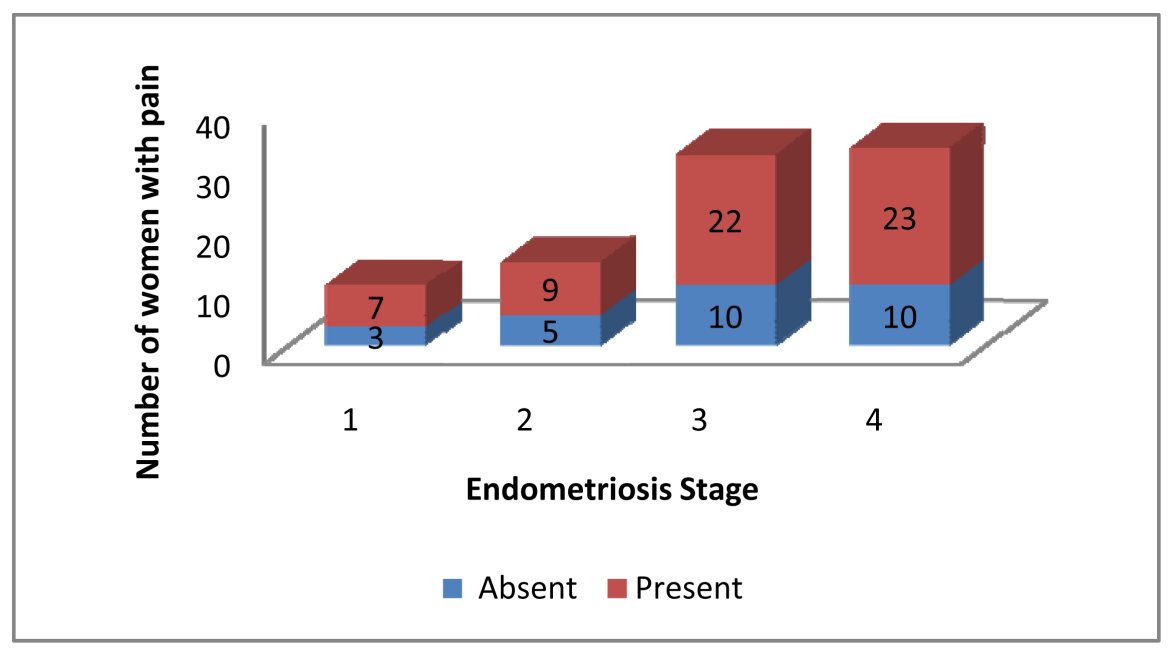

Figure 1. Association of pain with stage of disease. 
not suffer from pain of any type. Morphologically lesions were not any different in women with dyspareunia or dyschezia. On log regression analysis, there was no significant difference between the stages $\mathrm{A} \& \mathrm{~B}$ with respect to dysmenorrhea $(\mathrm{P}=0.89$, OR 1.075; CI 0.382 - 3.025). For dyspareunia at $\mathrm{p}=0.059$ (OR 2.7, CI $0.963-7.77$ ) though the result was statistically not significant, this association is considered clinically significant. Dyschezia was not present in any of the patients with stage A disease while 14 patients in stage B complained of the symptom. Nine women out of these 14, had obliteration of pouch of Douglas along with adherence of bowel to posterior surface of uterus. No significant association was found between the stage of disease or type of lesions with the duration of symptoms $(\mathrm{P}=0.768$, OR 1.167 , CI $0.238-5.725)$. Of the 89 patients with endometriosis, $48(60.75 \%)$ did not have a living issue (Figure 3), 44 had infertility (30 primary and 14 secondary) while 4 patients were unmarried. No significant difference was observed between the stage of disease and parity $(\mathrm{P}=0.897, \mathrm{OR}=$ 0.917, CI $0.245-3.424$ for Stage A; $\mathrm{P}=0.594$, OR $=0.750$, CI $0.260-2.163$ for stage B).

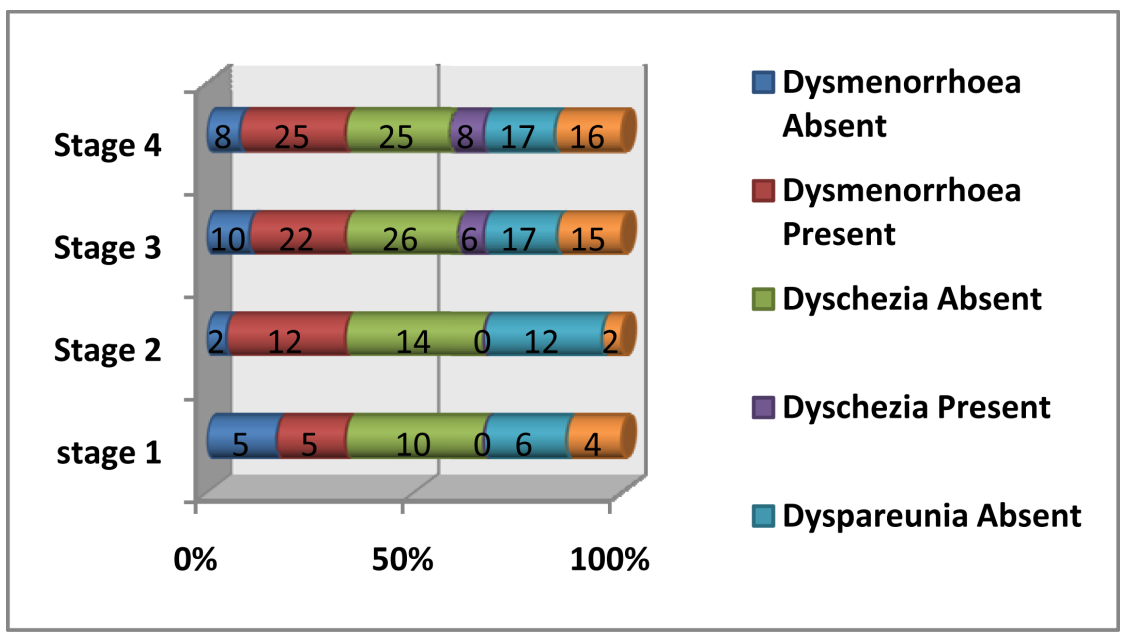

Figure 2. Association of stage with pain type.

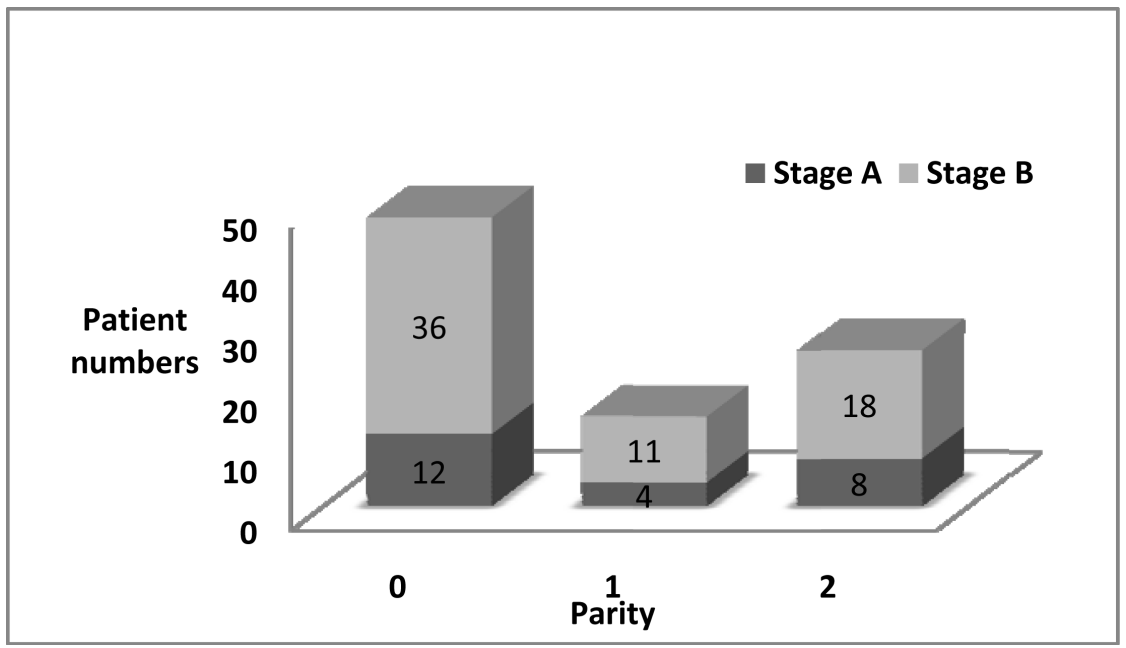

Figure 3. Parity and stage of endometriosis. 
Seventeen of 48 women with infertility also complained of chronic pelvic pain. All the 4 unmarried women were $<20$ years of age and complained of severe dysmenorrhoea; all of them had advanced stage 3 or 4 endometriosis at laparoscopy with bilateral endometrioma. One patient was also found to have a functioning non-communicating uterine rudimentary horn which had been excised.

Abnormal findings on ultrasound were seen in $65.16 \%$ of patients with endometriosis, the commonest finding being endometrioma $(\mathrm{n}=24)$ (Table 2). Transvaginal sonography had better predictability for stage B compared to Stage A disease $(\mathrm{P}=0.024$, OR 5.056, CI 1.241 - 20.592).

Two patients also complained of swelling in lower abdomen along with pain. While the cause was diagnosed to be caesarean scar endometriosis with ovarian endometrioma in one patient, the other had endometriotic implant on rectus sheath.

\section{Discussion}

Endometriosis remains a clinical enigma due to its variable presentation. Existence of relationship between endometriosis, chronic pelvic pain and infertility is widely accepted. Low incidence of disease in extremes of age and higher burden in reproductive years have been well documented by various authors [10] [11]. This was also observed in our study with mean age of presentation at 29.67 years. In the present study, most patients (73\%) had advanced stage disease at the time of presentation (Stage 3 and 4). This is in contrast to finding by other authors who reported early presentation in their case series [12]. We did not find any correlation of pain with the stage of disease. Lack of any positive correlation between symptoms and stage of disease has also been reported by Vercellini P et al. [13], Gruppo Italiano [14]. Obliteration of Pouch of Douglas in 9 out of 14 women with dyschezia in the present study suggests possible correlation between types of pain with anatomical site of lesion. This is in accordance with other studies [15] [16] which reported that severe dyspareunia and painful defecation during menses was associated with posterior DIE (deep infiltrating endometriosis) [15], and those with rectal or vaginal DIE lesions had increased severity of dysmenorrhea [17].

Infertility among women with endometriosis in our study was $31.46 \%$.The results are similar to Bellelis et al. who reported $40 \%$ infertility rate among study participants [18]. We found that primary infertility was more common than secondary infertility ( $30 \%$ vs 15\%), a finding similar to other descriptive studies [8] [15].

Nulliparity has been strongly associated with endometriosis. Most patients (53.93\%)

Table 2. USG Findings and stage of disease at laproscopy.

\begin{tabular}{ccccc}
\hline & \multicolumn{2}{c}{ STAGE A } & \multicolumn{2}{c}{ STAGE B } \\
\hline USG Findings & Stage 1 & Stage 2 & Stage 3 & Stage 4 \\
\hline No abnormality & 6 & 7 & 12 & 6 \\
Endometrioma & 1 & 2 & 10 & 11 \\
Others & 3 & 5 & 10 & 16 \\
\hline
\end{tabular}


in the present study were nulliparous. It is not clear whether infertile women are at a higher risk of endometriosis or endometriosis is cause infertility [18]. But the finding possibly supports the retrograde menstrual reflux theory, as nulliparous women may not have cervical dilation which is associated with labour and delivery [19]: hence providing the path of low resistance for outflow of menstrual blood.

Association between ovarian endometrioma and dysmenorrhoea has always been controversial. We found that although endometrioma was a common finding in patients presenting with dysmenorrhoea yet the association was not statically significant as was the finding in some reports [20]-[22]. This is in contrast to study conducted by Fedele et al. [4], Muzii et al. 1997 [7] who reported significant association between ovarian endometrioma and chronic pelvic pain.

Transvaginal ultrasound is a reasonably good method for of ovarian endometriosis. Abnormal USG findings were seen in $65.16 \%$ of patients in our study, most frequent of which was presence of endometrioma with typical ground glass appearance. Sensitivity of ultrasound to diagnose abnormality increased with advanced stage of disease (Table 2) as also observed by other authors [19] [23]. But still there was a significant proportion of cases (34.8\%) that actually had endometriosis but no abnormality was detected on ultrasound. This could be because of lack of adequate resolution of TVS to detect presence of deep infiltrating lesions or superficial peritoneal implants or adhesions. Hence, it would seem that as a diagnostic modality, ultrasound has a limited role for confirming endometriosis other than endometrioma. In a recent Cochrane review (2016), concluded that none of imaging modalities including MRI and transvaginal ultrasound were able to detect overall pelvic endometriosis with enough accuracy to be able to replace laparoscopy. But specifically for endometrioma, TVS was found to have high specificity $0.96 \%(95 \%$ CI $0.92,0.99)$ and hence, it qualified the criteria for a replacement test [24].

An important observation in our study was that out of 24 patients diagnosed with endometrioma on transvaginal ultrasound $21(87.5 \%)$ had advanced stage disease ( 3 \& 4). Of these 16 patients (66.6\%) were infertile. Finding of ovarian endometrioma on ultrasound in a patient within fertility should raise the strong suspicion of moderate to severe form of endometriosis. The place of a non-invasive and relatively cost effective investigation i.e. USG for diagnosis or raising suspicion of pelvic endometriosis has been highlighted in the present study.

\section{Conclusion}

Endometriosis is a common disorder of reproductive age women and remains a difficult clinical problem due to its variable presentation. Clinical symptoms don't correlate well with stage and severity of disease. Ultrasound is reliable for diagnosis of cystic ovarian endometriosis. Finding of endometrioma on ultrasound strongly suggests advanced form of disease.

\section{References}

[1] Fedele, L., Parazzini, F., Bianchi, S., Arcaini, L. and Candiani, G.B. (1990) Stage and Local- 
ization of Pelvic Endometriosis and Pain. Fertility and Sterility, 53, 155-158.

http://dx.doi.org/10.1016/S0015-0282(16)53232-4

[2] Mahmood, T.A., Templeton, A.A., Thomson, L. and Fraser, C. (1991) Menstrual Symptoms in Women with Pelvic Endometriosis. British Journal of Obstetrics and Gynaecology, 98, 558-563. http://dx.doi.org/10.1111/j.1471-0528.1991.tb10370.x

[3] Ripps, B.A. and Martin, D.C. (1991) Focal Pelvic Tenderness, Pelvic Pain and Dysmenorrhea in Endometriosis. Journal of Reproductive Medicine, 36, 470-472.

[4] Fedele, L., Bianchi, S., Bocciolone, L., Di Nola, G. and Parazzini, F. (1992) Pain Symptoms Associated with Endometriosis. Obstetrics \& Gynecology, 79, 767-769.

[5] Stovall, D.W., Bowser, L.M., Archer, D.F. and Guzick, D.S. (1997) Endometriosis Associated Pelvic Pain: Evidence for an Association between the Stage of Disease and a History of Chronic Pelvic Pain. Fertility and Sterility, 68, 13-18.

http://dx.doi.org/10.1016/S0015-0282(97)81468-9

[6] Milingos, S., Protopapas, A., Kallipolitis, G., Drakakis, P., Loutradis, D., Liapi, A. and Antsaklis, A. (2006) Endometriosis in Patients with Chronic Pelvic Pain: Is Staging Predictive of the Efficacy of Laparoscopic Surgery in Pain Relief? Gynecologic and Obstetric Investigation, 62, 48-54. http://dx.doi.org/10.1159/000092023

[7] Muzii, L., Marana, R., Pedulla, S., Catalano, G.F. and Mancuso, S. (1997) Correlation between Endometriosis-Associated Dysmenorrhea and the Presence of Typical or Atypical Lesions. Fertility and Sterility, 68, 19-22. http://dx.doi.org/10.1016/S0015-0282(97)81469-0

[8] The Practice Committee of the American Society of Reproductive Medicine (2012) Endometriosis and Infertility: A Committee Opinion. Fertility and Sterility, 98, 591-598.

http://dx.doi.org/10.1016/j.fertnstert.2012.05.031

[9] Nnoaham, K.E., Hummelshoj, L., Kennedy, S.H., Jenkinson, C. and Zondervan, K.T., World Endometriosis Research Foundation Women's Health Symptom Survey Consortium (2012) Developing Symptom-Based Predictive Models of Endometriosis as a Clinical Screening Tool: Results from a Multicenter Study. Fertility and Sterility, 98, 692-701. http://dx.doi.org/10.1016/j.fertnstert.2012.04.022

[10] Arruda, M.S., Petta, C.A., Abrão, M.S. and Benetti-Pinto, C.L. (2003) Time Elapsed from the Onset of Symptoms to Diagnosis of Endometriosis in a Cohort Study of Brazilian Women. Human Reproduction, 18, 756-759. http://dx.doi.org/10.1093/humrep/deg136

[11] Kuohung, W., Jones, G.L. and Vitonis, A.F. (2002) Characteristics of Patients with Endometriosis in the United States and the United Kingdom. Fertility and Sterility, 78, 767-772. http://dx.doi.org/10.1016/S0015-0282(02)03342-3

[12] Khawaja, U.B., Khawaja, A.A., Gowani, S.A., Shoukat, S., Ejaz, S., Ali, F.N., et al. (2009) Frequency of Endometriosis among Infertile Women and Association of Clinical Signs and Symptoms with the Laparoscopic Staging of Endometriosis. Journal of Pakistan Medical Association, 59, 30-34.

[13] Vercellini, P., Trespidi, L., De Giorgi, O., Cortesi, I., Parazzini, F. and Crosignani, P.G. (1996) Endometriosis and Pelvic Pain: Relation to Disease Stage and Localization. Fertility and Sterility, 65, 299-304. http://dx.doi.org/10.1016/S0015-0282(16)58089-3

[14] GruppoItaliano per lo Studio dell'Endometriosi (2001) Relationship between Stage, Site and Morphological Characteristics of Pelvic Endometriosis and Pain. Human Reproduction, 16, 2668-2671. http://dx.doi.org/10.1093/humrep/16.12.2668

[15] Chapron, C., Fauconnier, A., Dubuisson, J.B., Barakat, H., Vieira, M. and Breart, G. (2003) Deep Infiltrating Endometriosis: Relation between Severity of Dysmenorrhoea and Extent of Disease. Human Reproduction, 18, 760-766. http://dx.doi.org/10.1093/humrep/deg152 
[16] Leng, J.H., Lang, J.H., Dai, Y., Li, H.J. and Li, X.Y. (2007) Relationship between Pain Symptoms and Clinico-Pathological Features of Pelvic Endometriosis. Chinese Journal of Obstetrics and Gynecology, 42, 165-168.

[17] Chapron, C., Barakat, H., Fritel, X., Dubuisson, J.B., Breart, G. and Fauconnier, A. (2005) Presurgical Diagnosis of Posterior Deep Infiltrating Endometriosis Based on a Standardized Questionnaire. Human Reproduction, 20, 507-513. http://dx.doi.org/10.1093/humrep/deh627

[18] Bellelis, P., Dias Jr., J.A. Podgaec, S., Gonzales, M., Baracat, E. and Abrão, M. (2010) Epidemiological and Clinical Aspects of Pelvic Endometriosis-A Case Series. Revista da Associação Médica Brasileira, 56, 467-471. http://dx.doi.org/10.1590/S0104-42302010000400022

[19] Cramer, D.W. and Missmer, S.A. (2002) The Epidemiology of Endometriosis. Annals of the New York Academy of Sciences, 955, 11-22. http://dx.doi.org/10.1111/j.1749-6632.2002.tb02761.x

[20] Porpora, M.G., Koninckx, P.R., Piazze, J., Natili, M., Colagrande, S. and Cosmi, E.V. (1999) Correlation between Endometriosis and Pelvic Pain. Journal of the American Association of Gynecologic Laparoscopists, 6, 429-434. http://dx.doi.org/10.1016/S1074-3804(99)80006-1

[21] Chapron, C., Fauconnier, A., Dubuisson, J.B., Barakat, H., Vieira, M. and Breart, G. (2003) Deep Infiltrating Endometriosis: Relation between Severity of Dysmenorrhoea and Extent of Disease. Human Reproduction, 18, 760-766. http://dx.doi.org/10.1093/humrep/deg152

[22] Koninckx, P.R., Meuleman, C., Demeyere, S., Lesaffre, E. and Cornillie, F.J. (1991) Suggestive Evidence That Pelvic Endometriosis Is a Progressive Disease, Whereas Deeply Infiltrating Endometriosis Is Associated with Pelvic Pain. Fertility and Sterility, 55, 759-765. http://dx.doi.org/10.1016/S0015-0282(16)54244-7

[23] Exacoustos, C., Zupi, E., Carusotti, C., Rinaldo, D., Marconi, D., Lanzi, G., et al. (2003) Staging of Pelvic Endometriosis: Role of Sonographic Appearance in Determining Extension of Disease and Modulating Surgical Approach. Journal of the American Association of Gynecologic Laparoscopists, 10, 378-382. http://dx.doi.org/10.1016/S1074-3804(05)60266-6

[24] Nisenblat, V., Bossuyt, P.M.M., Farquhar, C., Johnson, N. and Hull, M.L. (2016) Imaging Modalities for the Non-Invasive Diagnosis of Endometriosis. Cochrane Database of Systematic Reviews, Article Number: CD009591. http://dx.doi.org/10.1002/14651858.cd009591.pub2

Submit or recommend next manuscript to SCIRP and we will provide best service for you:

Accepting pre-submission inquiries through Email, Facebook, LinkedIn, Twitter, etc. A wide selection of journals (inclusive of 9 subjects, more than 200 journals)

Providing 24-hour high-quality service

User-friendly online submission system

Fair and swift peer-review system

Efficient typesetting and proofreading procedure

Display of the result of downloads and visits, as well as the number of cited articles

Maximum dissemination of your research work

Submit your manuscript at: http://papersubmission.scirp.org/

Or contact ojog@scirp.org 